\title{
Large-Scale Cu Nanowire Synthesis by PVP-Ethylene Glycol Route
}

\author{
Jhon L. Cuya Huaman (D), Iori Urushizaki, and Balachandran Jeyadevan \\ Department of Material Science, School of Engineering, The University of Shiga Prefecture, Hikone, Japan \\ Correspondence should be addressed to Jhon L. Cuya Huaman; cuya.j@office.usp.ac.jp
}

Received 14 March 2018; Revised 29 May 2018; Accepted 12 June 2018; Published 8 August 2018

Academic Editor: Elisabetta Comini

Copyright ( 92018 Jhon L. Cuya Huaman et al. This is an open access article distributed under the Creative Commons Attribution License, which permits unrestricted use, distribution, and reproduction in any medium, provided the original work is properly cited.

$\mathrm{Cu}$ nanowire (NW) is a promising cost-benefit conducting material that could be considered for the development of transparent conducting films (TCF). However, the development of $\mathrm{Cu} \mathrm{NW}$ as an alternating material for $\mathrm{Ag}$ or Au is not only limited by its stability in atmospheric conditions in the nanometer range but also due to the nonavailability of a simple synthetic route to produce them in high yields and in large-scale. Here, a scheme to synthesize $\mathrm{Cu} N W$ s by reducing $\mathrm{Cu}$ nitrate in a $\mathrm{Cl}^{-}$ionpolyvinylpyrrolidine- (PVP-) ethylene glycol (EG) system is proposed. Cu NWs with average diameter around $60 \mathrm{~nm}$ and average length of about $40 \mu \mathrm{m}$ was obtained under optimized experimental conditions. Furthermore, the formation of $\mathrm{Cu} \mathrm{NW}$ was elucidated to be through the progression of the following sequential reduction steps: at first, $\mathrm{Cu}$ ions underwent partial reduction to form spherical $\mathrm{Cu}_{2} \mathrm{O}$. Then, the spherical $\mathrm{Cu}_{2} \mathrm{O}$ particles were redissolved and reduced to metallic $\mathrm{Cu}^{0}$ atoms that subsequently formed the $\mathrm{Cu}$ seeds. Thereafter, $\mathrm{Cu}$ seeds underwent etching to form multiply-twinned particles (MTP). Finally, these Cu MTP grew unidirectionally to form metallic Cu NWs.

\section{Introduction}

In recent years, the development of TCF such as touching screens, thin-film solar cells, organic light-emitting diodes, and sensors using metallic NWs as an alternative conducting material for indium tin oxide is being researched intensively [1-3]. In fact, the optical and electrical properties of TCF prepared using Ag NWs with diameters $\sim 20 \mathrm{~nm}$ and lengths higher than $20 \mu \mathrm{m}$ have outperformed the ones prepared using commercial ITO and exhibited transmittance higher than $85 \%$ and electrical resistivity less than $45 \Omega /$ sq. $[2,3]$. However, the material cost and migration caused in moist conditions are considered detrimental to their use in TCF and researches on alternative metallic NWs are being considered. Consequently, the research on the development of $\mathrm{Cu}$ NWs are on the rise due to the availability of cheap and abundant resources, high electrical properties, and low migration problem despite the fact that $\mathrm{Cu}$ has showed low stability in moist and oxidizing atmospheres [4-8]. Consequently, several physical and chemical routes have been developed to synthesize $\mathrm{Cu} \mathrm{NWs}$; however, in most cases, the chemical routes are considered due to simplicity and scalability of these techniques in contrast to other routes [9-22]. Among the developed chemical techniques, aqueous synthetic route using hydrazine as the reducing agent is researched intensively [13-18]. However, this technique uses high concentrations of sodium hydroxide $(\mathrm{NaOH})$ and requires stringent washing technique to remove the alkali that could hamper the conductivity of $\mathrm{Cu}$ NWs due to surface oxidation. On the other hand, long alkyl amine-mediated synthesis of $\mathrm{Cu}$ NWs has gained importance due to the possibility of dispersing and storing the products in organic solvents that could avoid rapid oxidation [19-22]. In this method, alkyl amines function as the reducing, protecting, and growth-controlling agent. The adsorption of alkyl amine on specific $\{100\}$ planes of $\mathrm{Cu}$ seeds facilitates the unidirectional growth the seeds in the [110] direction [20]. Though the organic route is considered simpler than the aqueous route, the heterogeneous dispersion of NWs has been observed when the suspension was deposited on substrates; thus, additional processing steps such as ligand exchange are required to enhance the dispersing ability of NWs in polar and nonpolar solvents. Even though the issues such as inhibition of oxidation and enhancement in the stability 
of suspension remain, large-scale synthesis is also considered a serious issue that needs to be resolved.

On the other hand, the success of Ag NWs as an alternative material for ITO in TCF could be ascribed to their largescale production using a simple and scalable polyol process that enables dimensional control of NWs through the control of concentrations of $\mathrm{Cl}^{-}$ion, $\mathrm{AgNO}_{3}$, and PVP in ethylene glycol [23-26]. In addition, the fine tuning of the dimensional properties of NWs such as the length and diameter could also be achieved by introducing chemical additives at various stages of the process [24-28]. However, it should be noted that the above technique has not been successfully applied to large-scale synthesis of $\mathrm{Cu}$ NWs with dimensional properties suitable for conductive electrodes, that is, $20 \mathrm{~nm}$ in diameter and $20 \mu \mathrm{m}$ in length $[2,3]$. One of the reasons could be the low redox potential of $\mathrm{Cu}$ ions compared to Ag ions, which requires the synthesis at elevated temperatures or the use of weak reducing agents such as either sodium hypophosphite or sodium borohydride along with alcohol that enhances the overall reducing ability of the system [29-31]. However, the products obtained were mostly $\mathrm{Cu}$ nanoparticles (NPs) and not $\mathrm{Cu}$ NWs. And also, unlike in the case of $\mathrm{Ag} \mathrm{NWs}$, the formation of intermediate phases such as cupric and cuprous compounds [32-34] seems to play an important role in determining the reduction rate, which is quite vital and decisive step defining the final morphology of metallic $\mathrm{Cu}$. $\mathrm{Cu} \mathrm{NWs}$ have been obtained in alkylamine-glucose or glycerol systems at relatively high temperatures [4]. Although, alkylamine enhanced the reducing ability of polyol and controlled the unidirectional growth on $\{100\}$ planes, this was not adequate to avoid the generation of NPs in large quantities. On the other hand, the synthesis of $\mathrm{Cu}$ NWs by using propylene glycol as reducing agent and PVP as surfactant has also been reported [35]. Here, the use of tetraphenylphosphonium chloride is considered to have played an important role in obtaining nanowires. Though the yield of $\mathrm{Cu}$ NWs was very low and their diameters were thick $(<300 \mathrm{~nm})$, this technique can be improved by considering stronger reducing agents.

In the case of Ag NWs in EG-PVP system, two closely related elements, namely, $\mathrm{Cl}^{-}$ions and PVP molecules that specifically adsorb on the $\{100\}$ planes of Ag NPs, are reported to facilitate the unidirectional growth of Ag seeds [23-26, 28, 36-40]. In addition, PVP molecules are reported to enhance the reduction of metal salts by forming complexes through coordination between metallic ions and $\mathrm{C}=\mathrm{O}$ groups and also stabilize the products subsequently [36, 37]. However, the specific adsorption of PVP for the unidirectional growth of metallic seeds is only realized at specific $\mathrm{Cl}^{-}$ion concentrations $[28,36,40]$. At conditions suitable for the reduction of $\mathrm{Ag}$ ions to metallic $\mathrm{Ag}, \mathrm{Cl}^{-}$ions control the morphology of Ag products through the etching processes that generate multitwinned Ag seeds. The etching mechanism that consists of selective removal of twinned structures into solution by the presence of an oxidative pair such as $\mathrm{Cl}^{-} / \mathrm{O}_{2}$ or $\mathrm{Fe}^{3+} / \mathrm{Fe}^{2+}$ was initially proposed by Wiley et al. [23]. They claimed that the shape of the particles can be controlled by controlling the degree of etching or in other words by controlling the concentration of $\mathrm{Cl}$ ions. For example, in the absence of $\mathrm{Cl}^{-}$ions, where the etching does not occur, the product will be constituted of spherical and polyhedral particles only. However, at higher $\mathrm{Cl}^{-}$ion concentrations, the total dissolution of nanoparticles occurs. Furthermore, at appropriate concentration of $\mathrm{Cl}^{-}$ions, the formation of MTP is facilitated and product becomes almost only of NWs.

Here, the synthesis of $\mathrm{Cu}$ NWs in high yield using the EG-PVP system under optimized conditions is reported. The formation mechanism of $\mathrm{Cu}$ NWs based on the analytical results acquired from the solution as well as the solids obtained during synthesis of Cu NWs using UV-visible spectroscopy (UV-Vis), scanning electron microscopy (SEM), and X-ray diffractometry (XRD) is also proposed. The study revealed that $\mathrm{Cu}$ NWs originated from the dissolution of the intermediate oxide compounds such as $\mathrm{Cu}_{2} \mathrm{O}$. The dissolution rate of $\mathrm{Cu}_{2} \mathrm{O}$ and the subsequent reduction to metallic $\mathrm{Cu}$ were considered to be the critical and rate determining steps for the formation of $\mathrm{Cu} \mathrm{NW}$.

\section{Materials and Methods}

2.1. Preparation of $\mathrm{Cu} N W s$. $\mathrm{Cu}\left(\mathrm{NO}_{3}\right)_{2} \cdot 3 \mathrm{H}_{2} \mathrm{O}(10 \mathrm{mM})$, polyvinylpyrrolidone (PVPK30, 0 to $75 \mathrm{mM}$ considering the monomer unit), and cetyltrimethylammonium chloride (CTAC, 0 to $10 \mathrm{mM}$ ) were introduced into a $200 \mathrm{ml}$ twonecked flask containing $100 \mathrm{ml}$ of EG. This solution was heated between 172 and $186^{\circ} \mathrm{C}$ for $4 \mathrm{~h}$ under continuous mechanical stirring and $\mathrm{N}_{2}$ purging (0 to $200 \mathrm{ml} / \mathrm{min}$ ). The solid products were collected by centrifuging the suspension at $3000 \mathrm{rpm}$ for $10 \mathrm{~min}$. The recovered sediment was washed by methanol several times, dispersed in methanol and stored.

2.2. Characterization of $\mathrm{Cu}$ NWs. Identification of the crystal phases present in the sediment was analyzed by X-ray diffractometry (XRD, Rigaku SmartLab) using $\mathrm{Cu} \mathrm{K} \alpha$ in the angle $2 \theta$ ranging from 20 to 80 degrees. The optical properties of $\mathrm{Cu}$ NWs suspended in methanol were evaluated using ultraviolet visible spectroscopy (UV4900, Rigaku) in the range of 300 to $800 \mathrm{~nm}$ using quartz cells. The morphology of the products was examined by using field emission scanning electron microscopy (FE-SEM, Hitachi 4400) and transmission electron microscopy (TEM, Hitachi-8100). The adsorption of PVP on the $\mathrm{Cu}$ NW surface was verified by Fourier transformed infrared spectroscopy (FT-IR) in transmittance mode in the range of 500 to $4000 \mathrm{~cm}^{-1}$ (Nicolet iS5, Thermo Scientific), and the concentration of PVP attached to the NW surface was determined by thermogravimetry (TG) under $\mathrm{N}_{2}$ gas flow from room temperature to $500^{\circ} \mathrm{C}$ by heating at the rate of $10^{\circ} \mathrm{C} / \mathrm{min}$ using TG8120-Shimadzu device.

\section{Results and Discussion}

Taking the experimental conditions to obtain Ag NWs in EGPVP system into consideration, the tuning of $\mathrm{Cl}^{-}$ion concentration was considered vital to control the etching mechanism and the subsequent formation of NWs. Thus, in the first instance, the concentration of $\mathrm{Cl}^{-}$ions required to obtain NWs was examined while keeping the concentration of 
PVP constant. And then, the influences of PVP concentration and other parameters such as the reducing atmosphere and temperature were also studied.

\subsection{Influence of Halide Ion Source and Its Concentration on} $\mathrm{Cu} \mathrm{NW}$ Formation. Figure 1 shows the SEM images of $\mathrm{Cu}-$ based products obtained in the EG-PVP system using 0.5 to $2.5 \mathrm{mM}$ of CTAC as the source of $\mathrm{Cl}^{-}$ions. At $\mathrm{Cl}^{-}$ion concentration less than $0.5 \mathrm{mM}$, Cu nitrate was reduced by ethylene glycol to irregular and faceted metallic $\mathrm{Cu}$ particles ranging between 1 and $2 \mu \mathrm{m}$ along with few rods. When the concentration of $\mathrm{Cl}^{-}$ions ranged between 0.5 and $1.0 \mathrm{mM}$, the $\mathrm{Cu}$ particles became larger in size, and rods, plates, and triangular crystals were also observed (Figure 1(a)). The formation of $\mathrm{Cu}$ particles with different shapes could be due to presence of twinned $\mathrm{Cu}$ crystals that were not etched sufficiently due to the deficiency of $\mathrm{Cl}^{-}$ions. A remarkable change was observed when the alcoholic solution contained $1.0 \mathrm{mM}$ CTAC; the product was constituted mainly of thicker rods with an average aspect ratio (length/diameter) of 10 and small quantities of $\mathrm{Cu}$ particles with triangular facets that originated from decahedral or icosahedral crystals (Figure 1(b)).

When $\mathrm{Cl}^{-}$ion concentration reached $1.25 \mathrm{mM}$, the product was constituted only of $\mathrm{Cu}$ NWs (Figure 1(c)). Under these conditions, the average diameter and length of NWs were $74.1 \mathrm{~nm}$ and $31.5 \mu \mathrm{m}$, respectively (aspect ratio of 423). However, when the concentration of $\mathrm{Cl}^{-}$ion concentration resulted to be too high, the shape of NW was not retained and the yield decreased progressively (Figure 1(d)) and disappeared totally at $10 \mathrm{mM}$. On the contrary, micrometer-sized spherical particles were formed at higher concentration of $\mathrm{Cl}^{-}$ions (Figure 1(d)). Usually in the presence of high concentrations of $\mathrm{Cl}^{-}$ions, the formation of nanocubes is favored as in the case of Ag NPs due to the preferential adsorption on the $\{100\}$ planes $[23,24,28]$; however, this was not observed here. The XRD pattern of the spherical particles corresponded to the cubic phase of $\mathrm{Cu}_{2} \mathrm{O}$. This suggests that the reduction of $\mathrm{Cu}_{2} \mathrm{O}$ to $\mathrm{Cu}$ was delayed or reduction and dissolution occurred repeatedly under high concentration of CTAC and subsequently neither the formation of $\mathrm{Cu}$ NWs nor nanocubes was realized.

The above results suggested that at low $\mathrm{Cl}^{-}$ion concentrations, the reduction rate of $\mathrm{Cu}$ was too high for the seeds to undergo etching to generate preferential planes prior to growth, resulting in the formation of irregular and faceted nanostructures. On the other hand, at high $\mathrm{Cl}^{-}$ion concentrations, the etching was too strong and the concentration of $\mathrm{Cu}$ ions in the solution became high and led to the formation of spherical shaped $\mathrm{Cu}_{2} \mathrm{O}$ particles (Figure $1(\mathrm{e})$ ). Thus, the optimum $\mathrm{Cl}$ concentration was determined to be around $1.25 \mathrm{mM}$, or in other words, the $\mathrm{Cl} / \mathrm{Cu}$ molar ratio was 0.125 . This value was relatively high compared to the one used by Whitcomb, which is 0.026 [35]. Although, the low concentration of $\mathrm{Cl}^{-}$ions could be one of the reasons for low yield, the formation of insoluble or partially soluble intermediate compound, $\mathrm{CuCl}$ could be another. Though the presence of $\mathrm{CuCl}$ was not detected when the concentration of $\mathrm{Cl}^{-}$ions was low, their presence was confirmed in the structural and morphological analysis in the products obtained during the synthesis of $\mathrm{Cu}$ NWs under high CTAC concentrations $(5 \mathrm{mM})$ (Figure $\mathrm{S} 1$ ).

Then, to determine the influence of halide type on the formation of NWs, CTAC was replaced by equal concentrations of sodium fluoride $(\mathrm{NaF})$, sodium chloride $(\mathrm{NaCl})$, cetyltrimethylammonium bromide (CTAB), and potassium iodide (KI). As observed in the SEM photographs shown in Figures 1(f)-1(i), high yield of NWs was obtained in $\mathrm{NaCl}$ and CTAB cases. The above results suggested that the optimal halide concentration is very vital than the type or source of halide for the formation of Cu NWs in high yield. On the other hand, the formation of cuprous halides and their solubility product constants (Ksp) [41] could be an important factor to consider in the control of the final structure and the complete reduction of $\mathrm{Cu}$ salts as shown in Figure 1(j). Thus, the synthesis of high-yield $\mathrm{Cu}$ NWs proceeded in the following order:

$$
\mathrm{CuCl}\left(1.72 \times 10^{-7}\right)>\mathrm{CuBr}\left(6.27 \times 10^{-9}\right)>\operatorname{CuI}\left(1.27 \times 10^{-12}\right) .
$$

Hence, the reduction and formation of $\mathrm{Cu}$ NWs is favored at high solubility of intermediate products in the solvent as in the cases of $\mathrm{CuCl}$ and $\mathrm{CuBr}$. But, in the case of low solubility $\mathrm{CuI}$, the products resulted to be a mixture of $\mathrm{CuI}$, $\mathrm{Cu}_{2} \mathrm{O}$, and $\mathrm{Cu}$ phases (Figure S2). On the other hand, in the case of highly soluble $\mathrm{CuF}$ and the instability to form $\mathrm{CuF}_{2}$ enhances the formation of $\mathrm{Cu}$ NPs than $\mathrm{Cu}$ NWs.

The formation of NWs is influenced by the control over the reduction of $\mathrm{Cu}$ ions to form metallic $\mathrm{Cu}$ seeds and their subsequent etching to form MTPs that facilitate the formation of NWs. The dimensional properties of the NW are influenced very much by the unidirectional growth facilitated by the preferential adsorption of the capping agent on the crystal planes of the NWs. Thus, the role of the capping agent on the yield as well as the dimensional properties of Cu NWs will be discussed in the next section.

3.2. Influence of PVP on the Yield and Dimensional Properties of $\mathrm{Cu} N W$ s. The molecular weight and concentration of PVP have been reported to control the yield and dimensions of NWs [36-39] due to their preferential adsorption on $\{100\}$ planes of metallic surface compared to $\{111\}$. Thus, the effect of PVP concentration on the synthesis of $\mathrm{Cu}$ NWs at the reaction temperature of $182^{\circ} \mathrm{C}$ is investigated, while keeping $\mathrm{Cl}^{-} / \mathrm{Cu}^{2+}$ molar ratio and the amount of $\mathrm{N}_{2}$ purged constant. Figure 2 shows that decreasing the PVP concentration facilitated the formation of irregular-shaped $\mathrm{Cu}$ NPs at the expense of $\mathrm{Cu}$ NWs. At low PVP concentration of $25 \mathrm{mM}$, the nucleus grew isotropically due to insufficient concentration of capping agent. In contrast, at higher PVP concentration of $75 \mathrm{mM}$, the $\mathrm{Cu}$ NWs became thicker and shorter. When the concentration was increased further, only NPs were formed. This is believed due to the nonpreferential adsorption of PVP molecules on the crystal faces of $\mathrm{Cu}$ NPs, even on the $\{111\}$ planes that facilitate the unidirectional growth of NWs as shown in Figure $2(\mathrm{~g})$. The FT-IR spectra of pure PVP and the $\mathrm{Cu}$ NWs are shown in 

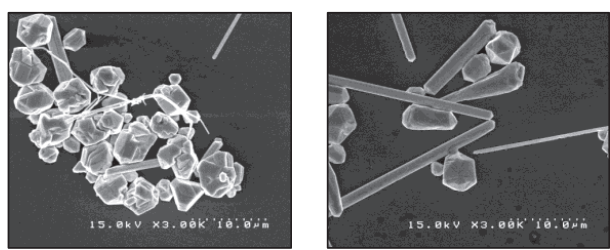

(a)

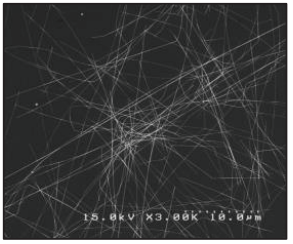

(c)

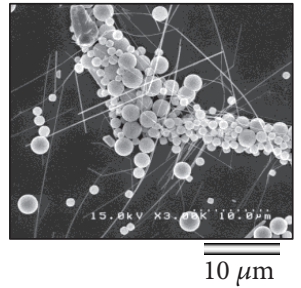

(d)

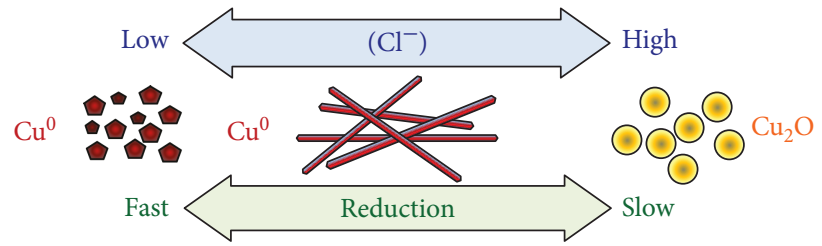

(e)

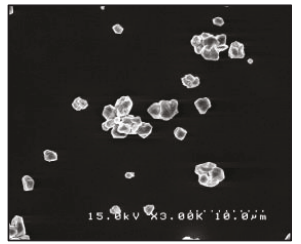

(f)

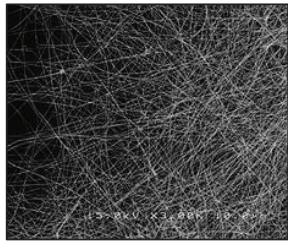

(g)

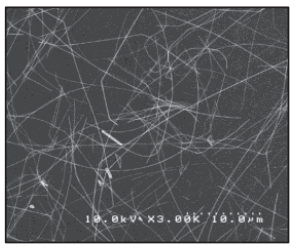

(h)

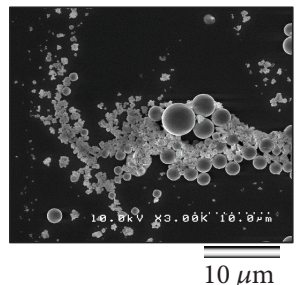

(i)

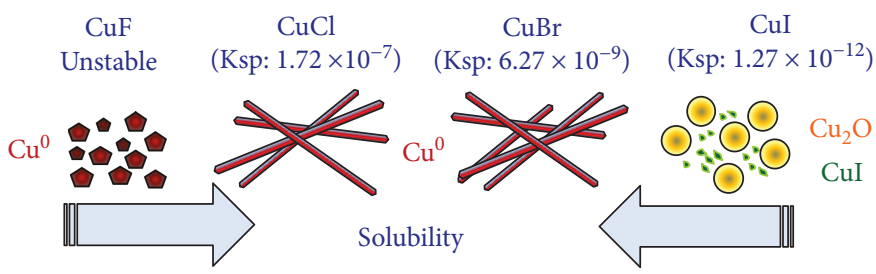

(j)

FIGURE 1: SEM images of Cu nanostructures obtained by reducing Cu nitrate in EG-PVP system in the presence of (a) 0.5, (b) 1.0, (c) 1.25, and (d) $2.5 \mathrm{mM}$ of CTAC and (e) a schematic illustration showing the effect of $\mathrm{Cl}^{-}$ion concentration in the formation of Cu NWs. SEM images of halide type in the synthesis of Cu NWs: (f) NaF, (g) NaCl, (h) CTAB, and (i) KI at a concentration of $1.25 \mathrm{mM}$ and (j) a schematic illustration that shows the effect of $\mathrm{Ksp}$ of $\mathrm{Cu}(\mathrm{I})$ halides in the formation of $\mathrm{Cu}$ NWs.

Figure 2(e), and the adsorption of PVP on the surface of NWs was confirmed. The spectrum of the NWs synthesized using the above technique shows absorption bands at $3400 \mathrm{~cm}^{-1}$ that could be ascribed to the overtone of $\mathrm{C}=\mathrm{O}$ bond. In addition, a band corresponding to $\mathrm{O}-\mathrm{H}$ groups at around $3500 \mathrm{~cm}^{-1}$ was also recorded. This could due to the presence of methanol used during washing. The stretching vibrations of $\mathrm{C}-\mathrm{H}$ and $\mathrm{C}=\mathrm{O}$ were observed at $2920 \mathrm{~cm}^{-1}$ and $1640 \mathrm{~cm}^{-1}$, respectively. Likewise, the absorption band corresponding to the stretching mode of $\mathrm{C}-\mathrm{N}$ was also observed at around $1300 \mathrm{~cm}^{-1}$. Furthermore, the PVP concentration adsorbed on the metallic surface was evaluated by thermogravimetry under $\mathrm{N}_{2}$ gas flow. As observed in Figure 2(f), the weight loss at temperatures below $180^{\circ} \mathrm{C}$ was around $8 \%$ and it could be ascribed to the removal of solvents such as methanol and adsorbed water. The weight loss between 180 and $200^{\circ} \mathrm{C}$ was steep and amounted to almost $15 \%$. Then, the weight loss progressed slowly and an additional $5 \%$ decrease was recorded at around $600^{\circ} \mathrm{C}$. These results suggested that PVP is strongly adsorbed on the $\mathrm{Cu}$ surface, and thermal treatments at higher temperatures are necessary to remove PVP molecules completely.

The optimal concentration of $\mathrm{Cl}^{-}$ions to facilitate the formation of MTPs and the optimal concentration of the capping agent for their subsequent growth have been studied in the previous sections. The diameter of the NW is very much influenced by the size of the seed as well as the MTP formed subsequently. This is believed to depend on the reduction and the etching rates of the reactions. The etching rate is believed to depend on the concentration of oxygen in the reaction system besides the concentration of $\mathrm{Cl}^{-}$ions. Thus, the influence of dissolved oxygen amount on the synthesis of $\mathrm{Cu}$ NWs is discussed in the next section.

3.3. Effect of the Amount of $\mathrm{N}_{2}$ Gas Flow on the Dimensional Properties of $\mathrm{Cu} N W s$. $\mathrm{Cl}^{-}$ions are assumed to form an oxidant $\mathrm{Cl}^{-} / \mathrm{O}_{2}$ pair with atmospheric oxygen that etches and dissolves the preferential planes of the nucleus to form MTP. Thus, the control of this mechanism is important to facilitate the formation rate of multitwinned metallic seeds 


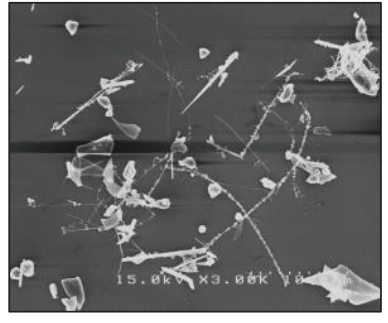

(a)

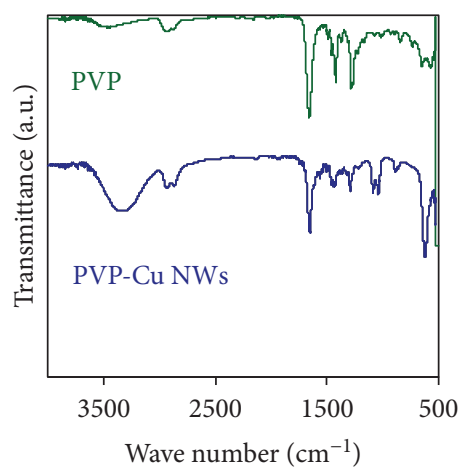

(e)

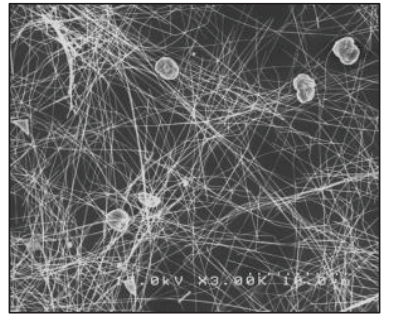

(b)

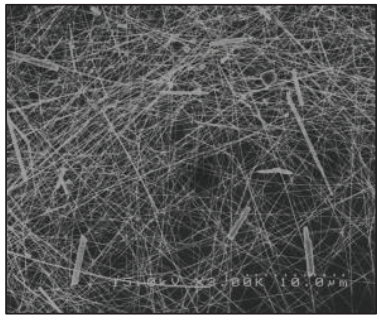

(c)

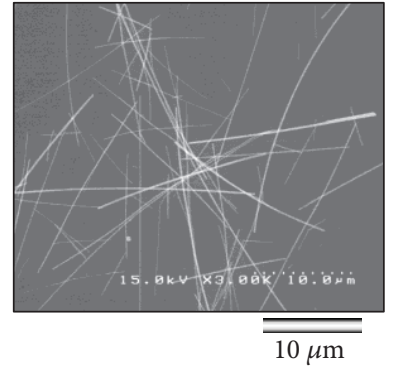

(d)

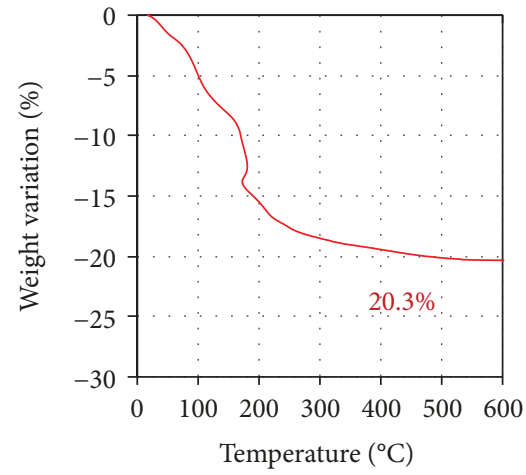

(f)

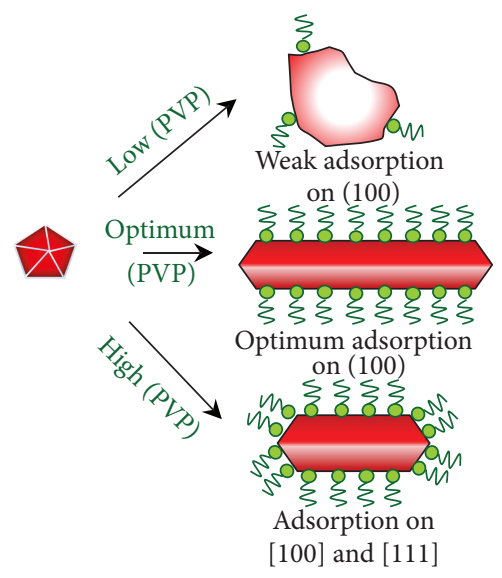

(g)

FIGURE 2: SEM images of Cu products obtained under different PVP concentrations: (a) 25, (b) 45, (c) 55, and (d) $75 \mathrm{mM}$ (scale bar: $10 \mu \mathrm{m}$ ). (e) FT-IR spectra of pure PVP and PVP-capped Cu NWs. (f) Thermal behavior of PVP-capped Cu NWs measured under $\mathrm{N}_{2}$ flow. (g) Schematic illustration describing the effect of concentration on the adsorption of PVP on Cu surface.

that grow unidirectionally in [110] orientation with the assistance of the preferential adsorption of the capping agent in $\{100\}$ planes. On the other hand, $\mathrm{Cu}$ NPs are unstable in air inclusively during synthesis and it is common that the reduction needs to be carried out under inert atmospheres using either $\mathrm{N}_{2}$ or Ar gas for the formation of $\mathrm{Cu}$ NWs $[42,43]$. The reaction atmosphere also influences the rate of the reduction. Thus, the change in the $\mathrm{N}_{2}$ flow rate between 0 and $150 \mathrm{ml} / \mathrm{min}$ influenced the morphology of Cu nanostructures as shown in Figure 3. It is clear that EG-PVP system can reduce $\mathrm{Cu}$ even in atmospheric conditions, and $\mathrm{Cu}$ NWs with diameters around $60.6 \mathrm{~nm}$ were obtained; however, nanometer-sized $\mathrm{Cu}$ oxide particles attached to the surface of NW were observed. On the other hand, at $\mathrm{N}_{2}$ flow rate of $150 \mathrm{ml} / \mathrm{min}$, the wires became thicker, $\sim 87.5 \mathrm{~nm}$, and the formation of nanocrystals with different sizes and shapes was observed at the expense of low yield of NWs. Here, the amount of $\mathrm{O}_{2}$ is reduced by adding $\mathrm{N}_{2}$ gas or other inert gases to the system, and subsequently, the selective dissolution of specific crystal planes could be inhibited favoring the growth of cubic crystals as observed in other metallic systems [44]. Thus, the formation of wires and the inhibition of oxidation of the synthesized NWs and NPs were realized under an optimum $\mathrm{N}_{2}$ flow rate of $100 \mathrm{ml} / \mathrm{min}$.

Optimization of the reaction atmosphere facilitated the control over the etching rate and also the stability of the $\mathrm{Cu}$ nanostructures. The average diameter and length of the NWs were $67.4 \mathrm{~nm}$ and $44 \mu \mathrm{m}$, respectively, and the aspect ratio was around 650 . However, for further reduction in the diameter, the reduction rate should be enhanced. One of the parameters that could enhance the reduction rate is the reaction temperature. Thus, the results obtained by varying the reaction temperature and their influence on the dimensional properties of $\mathrm{Cu} \mathrm{NW}$ are discussed in the next section.

3.4. Effect of Temperature. The synthesis of $\mathrm{Cu}$ NPs at low temperatures is realized only when additives that promote the reduction such as sodium hypophosphite monohydrate or sodium borohydride were added to the alcoholic system [29-31]. Increasing the reaction temperature near to the boiling point of ethylene glycol should enhance its reducing ability and facilitate the reduction of $\mathrm{Cu}^{2+}$ ions within a short period of time. Figure 4 and Figure S3 show the effect of reaction temperature on the synthesis of $\mathrm{Cu} N W s$, while all other experimental parameters were kept constant. At $174^{\circ} \mathrm{C}$, the formation of spherical $\mathrm{Cu}_{2} \mathrm{O}$ particles was concluded from SEM and XRD measurements (Figure S4). At this temperature, $\mathrm{Cu}^{2+}$ ions were reduced to form $\mathrm{Cu}_{2} \mathrm{O}$ but not to $\mathrm{Cu}$ metal even after a reaction time of $10 \mathrm{~h}$. Even though the formation $\mathrm{Cu} N W s$ was confirmed at $178^{\circ} \mathrm{C}$, the presence of $\mathrm{Cu}_{2} \mathrm{O}$ particles was also identified as shown in Figure 4(b). This suggested that the reaction temperature was not high enough to reduce the $\mathrm{Cu}$ ions completely. However, the products obtained at $182^{\circ} \mathrm{C}$ contained $\mathrm{Cu} N W s$ and free of oxide NPs (Figure 4(c)). At higher temperatures, high yield of thicker NWs free of NPs was obtained as shown in 


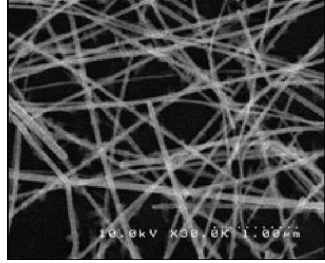

(a)

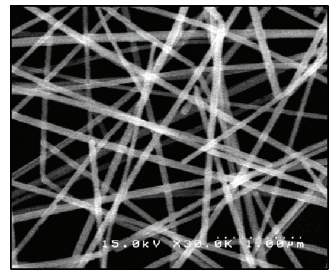

(c)

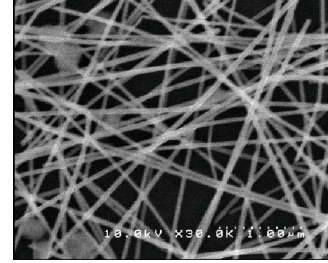

(b)

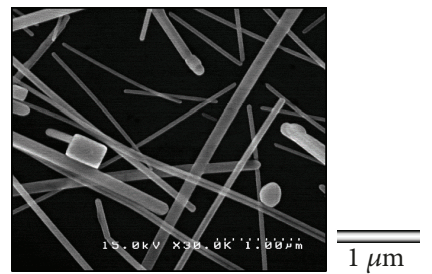

(d)

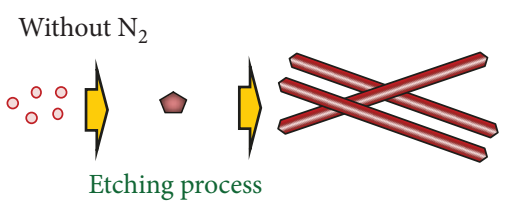

With $\mathrm{N}_{2}$

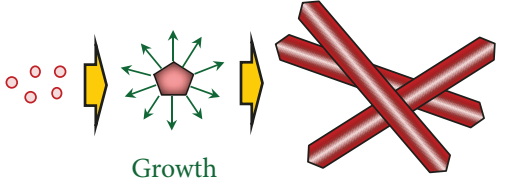

(e)

FIgURE 3: SEM images of $\mathrm{Cu}$ NWs synthesized under different $\mathrm{N}_{2}$ flow rates: (a) 0, (b) 50, (c) 100, and (d) $150 \mathrm{ml} / \mathrm{min}$. (e) Schematic illustration describing the effect of $\mathrm{N}_{2}$ flow rate in the formation of $\mathrm{Cu} \mathrm{NWs}$.

Figure 4(d). The kinetic of the reaction is expected to get accelerated at higher temperatures, and the formation of large particles is expected. In this case, the nanowires can grow in axial and radial directions easily. Thus, it was found that the diameter of $\mathrm{Cu}$ NWs obtained at different temperatures is influenced by the reaction temperature and NWs with average diameters $\sim 58 \mathrm{~nm}$ and $\sim 103 \mathrm{~nm}$ were obtained at $178^{\circ} \mathrm{C}$ and $186^{\circ} \mathrm{C}$, respectively. Figure $4(\mathrm{e})$ shows the effect of temperature in the reduction and formation of nanowires.

Our results demonstrated that $\mathrm{Cu}$ NWs can be synthesized in high yield in a $\mathrm{Cl}^{-}$ion-EG-PVP system by controlling the experimental parameter such as type and concentration of chloride source, concentration of PVP, the amount of $\mathrm{N}_{2}$ gas flow, and the reaction temperature. However, the physical characteristics of $\mathrm{Cu}$ NWs, specially the diameter, obtained under optimal conditions are not suitable to be used in the development of TCF. Thus, understanding the formation mechanism of $\mathrm{Cu}$ NWs is considered vital for further optimization of the process to develop of $\mathrm{Cu}$ NWs with high aspect ratio. In the next section, we attempted to elucidate the formation mechanism of NWs through structural and spectral analyses of the reaction solution and solids using XRD, UV-Vis, and SEM.

3.5. Formation Mechanism of $\mathrm{Cu}$ NWs. Figure 5 shows the XRD patterns of samples collected at different reaction times using the following experimental conditions: $10 \mathrm{mM} \mathrm{Cu}$ nitrate, $0.125 \mathrm{mM}$ of CTAC, $50 \mathrm{mM}$ of PVP, $182^{\circ} \mathrm{C}$, and under a $\mathrm{N}_{2}$ gas flow rate of $100 \mathrm{ml} / \mathrm{min}$. During heating, at temperatures below $150^{\circ} \mathrm{C}$, neither color variation of the alcoholic solution nor precipitation occurred. However, at temperatures between 150 and $160^{\circ} \mathrm{C}$, the color of the solution turned from light blue to orange with vigorous evolution of $\mathrm{NO}_{2}$ [45]. The XRD analysis of precipitated powders taken after completion of the evolution of gases showed a unique phase that matched well with cubic structured $\mathrm{Cu}_{2} \mathrm{O}$, and this phase remained stable even at higher temperatures as shown in Figure 5. It is clear that at this temperature, the reducing potential of ethylene glycol was only sufficient to reduce $\mathrm{Cu}^{2+}$ ions to $\mathrm{Cu}^{+}$, but not to $\mathrm{Cu}^{0}$ due to the presence of chloride which delayed the reduction as observed above. The $\mathrm{Cu}$ oxide phase remained for nearly $100 \mathrm{~min}$ at $182^{\circ} \mathrm{C}$, and then, the orange colored solution turned progressively to red caused by the transformation of $\mathrm{Cu}_{2} \mathrm{O}$ to $\mathrm{Cu}$ as confirmed by XRD. The reduction of $\mathrm{Cu}_{2} \mathrm{O}$ to $\mathrm{Cu}^{0}$ was totally completed in 10 minutes, and no further change was observed until the end of reaction. It is necessary to emphasize that intermediate phases such as hydroxide, chloride, or oxide $(\mathrm{CuO})$ were not observed during the reduction of $\mathrm{Cu}$ nitrate to $\mathrm{Cu}$ metal.

$\mathrm{Cu}_{2} \mathrm{O}$ and $\mathrm{Cu}$ NPs possess localized surface plasmon resonance at around 400 to $700 \mathrm{~nm}$ [32], which depends on the particle size and morphology. Thus, the progression of the reaction $\mathrm{Cu}^{2+} \rightarrow \mathrm{Cu}^{+} \rightarrow \mathrm{Cu}^{0}$ during heating at $182^{\circ} \mathrm{C}$ at different reaction times was analyzed using UV-Vis spectroscopy (Figure 5). At $50^{\circ} \mathrm{C}$ and at $150^{\circ} \mathrm{C}$, the UV-Vis spectra revealed a broad absorption peak at around $800 \mathrm{~nm}$ that could be ascribed to $\mathrm{Cu}^{2+}$ ions coordinated with ethylene glycol and disappeared totally when $\mathrm{Cu}_{2} \mathrm{O}$ was formed at higher temperatures. When the temperature reached $182^{\circ} \mathrm{C}$, a broad absorption band centered at around $440 \mathrm{~nm}$ was observed. This could be assigned to the presence of $\mathrm{Cu}_{2} \mathrm{O}$ particles, and this was not present in the spectra measured at temperatures lower than $182^{\circ} \mathrm{C}$ (inset Figure 5). After $60 \mathrm{~min}$, at $182^{\circ} \mathrm{C}$, the UV-Vis spectrum exhibited a shift in the peak corresponding to $\mathrm{Cu}_{2} \mathrm{O}$ from $440 \mathrm{~nm}$ to $470 \mathrm{~nm}$, which is believed due to particle growth. After $100 \mathrm{~min}$, at $182^{\circ} \mathrm{C}$, the color changed from orange to red and a new absorption peak appeared at $570 \mathrm{~nm}$. This could be as a consequence of $\mathrm{Cu}_{2} \mathrm{O}$ reduction to metallic $\mathrm{Cu}$ seeds [32]. The reduction reaction from $\mathrm{Cu}_{2} \mathrm{O}$ to $\mathrm{Cu}$ was relatively faster and the $\mathrm{Cu}_{2} \mathrm{O}$ absorption peak disappeared totally in 10 minutes leaving the peak corresponding to $\mathrm{Cu}$ NWs at $575 \mathrm{~nm}$ [21]. No change was observed after $120 \mathrm{~min}$, and absorption peak corresponding to $\mathrm{Cu}$ remained even at the end of the reaction.

The FE-SEM images of these samples (Figure 6) showed sphere-shaped $\mathrm{Cu}_{2} \mathrm{O}$ particles with a broad size distribution 


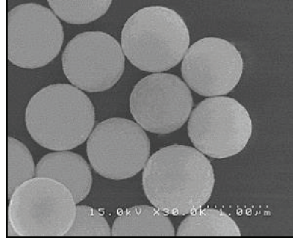

(a)

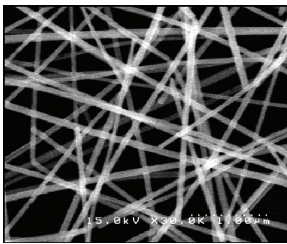

(c)

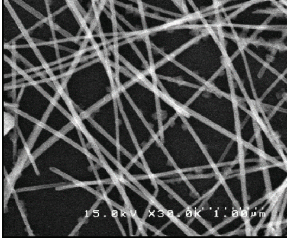

(b)

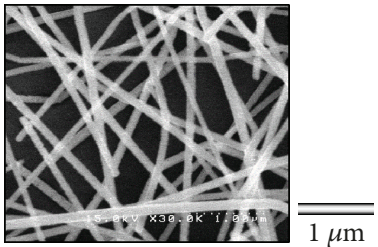

(d)

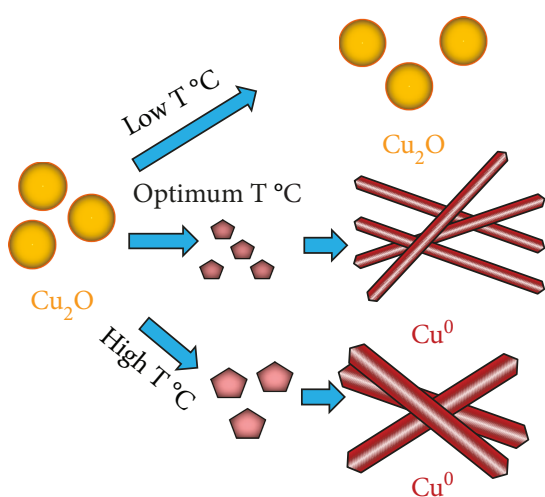

(e)

FIGURE 4: SEM images of $\mathrm{Cu}$ nanostructures obtained by reducing Cu nitrate in EG-PVP under different reaction temperatures: (a) 174, (b) 178 (c) 182 , and (d) $186^{\circ} \mathrm{C}$. (e) Schematic illustration of the effect of temperature on the formation of Cu NWs.
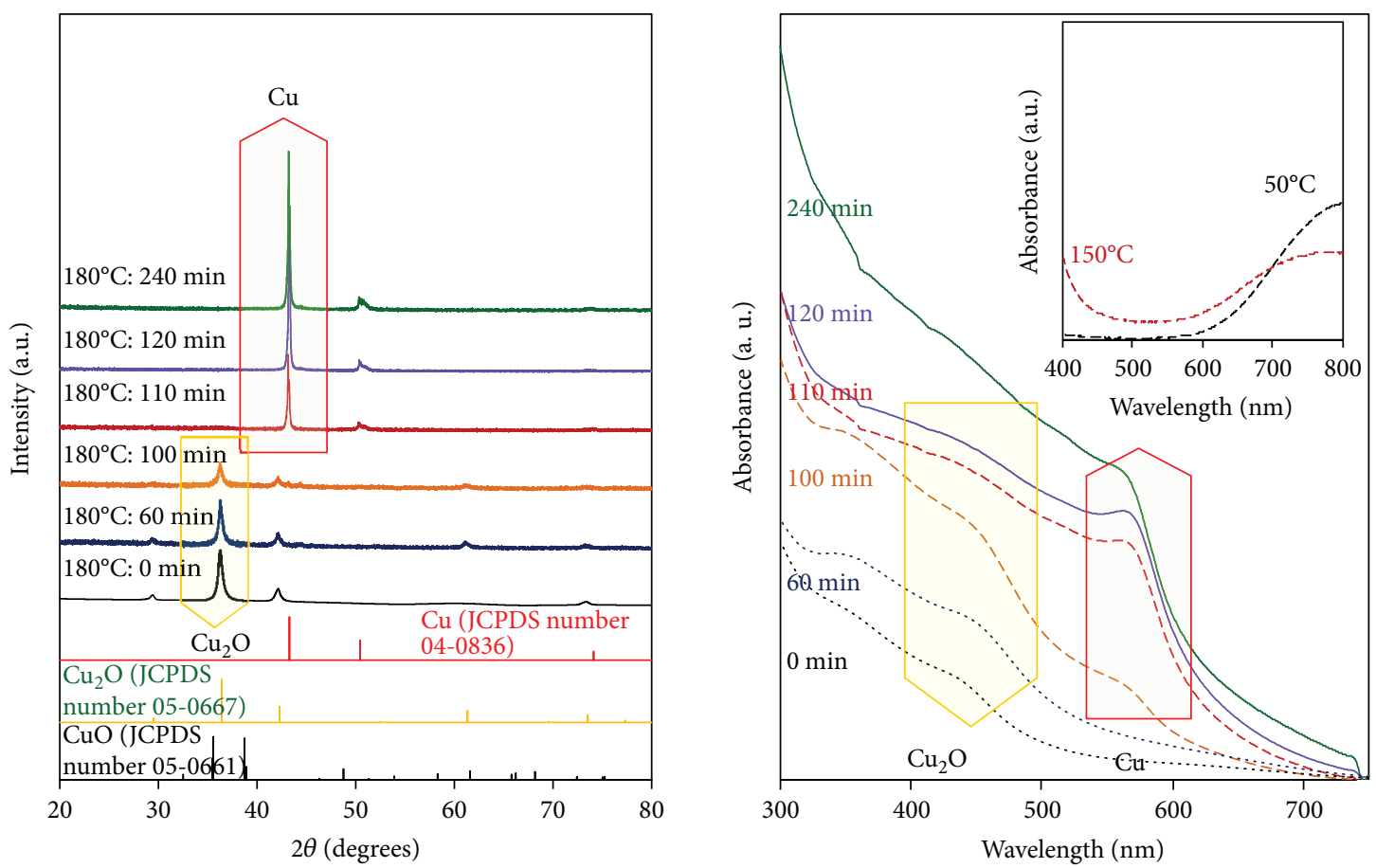

Figure 5: XRD patterns and UV-Vis spectra of $\mathrm{Cu}$ products collected during heating at $182^{\circ} \mathrm{C}$. Inset of UV-Vis spectra corresponds to the $\mathrm{UV}-\mathrm{V}$ is spectra of solution at 50 and $150^{\circ} \mathrm{C}$.

and an average size of $500 \mathrm{~nm}$ in the first few minutes of reaction at $182^{\circ} \mathrm{C}$. After 60 min of reaction, the spherical $\mathrm{Cu}_{2} \mathrm{O}$ particles began to dissolve as shown in the inset. However, the dissolved particles precipitated again as $\mathrm{Cu}_{2} \mathrm{O}$ and no other oxide phase was detected in the XRD pattern. As reaction progressed, the dissolution proceeded, and after $100 \mathrm{~min}$, the dissolved oxide was reduced to $\mathrm{Cu}$ metal in alcoholic solution. Then, due to the presence of $\mathrm{Cl}^{-}$ions and PVP, the metallic $\mathrm{Cu}$ seeds grew in a preferential direction, whereas rest of the $\mathrm{Cu}$ ions in the solution precipitated into small $\mathrm{Cu}_{2} \mathrm{O}$ cubes as observed in the inset. However, it is not clear whether these cubes originated during cooling the $\mathrm{Cu}^{2+}$ ions that remained in the solution or they existed prior to cooling. After 120 min of reaction, product constituted mainly of $\mathrm{Cu}$ NWs; however, the presence of $\mathrm{Cu}_{2} \mathrm{O}$ on the NW surfaces still remained. At the end of reaction, $\mathrm{Cu}$ NWs were the unique nanostructure. The diameter and length were $\sim 72 \mathrm{~nm}$ and 39 microns (aspect ratio of $\sim 540$ ), respectively. The TEM analysis and the selected area electron diffraction (SAED) of one section of $\mathrm{Cu}$ NWs are shown in Figures 6(g) and 6(h). The microphotographs showed that the NW had an average diameter of $71 \mathrm{~nm}$ and grew in the [110] direction [20]. Likewise, the sample exhibited diffraction spots corresponding to $\mathrm{Cu}_{2} \mathrm{O}$ phase. A careful observation of the microphotograph 


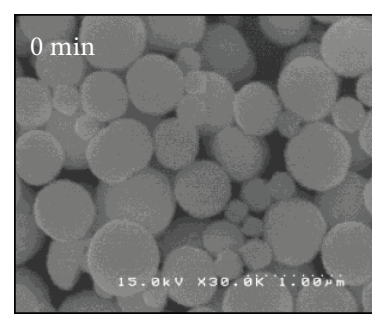

(a)

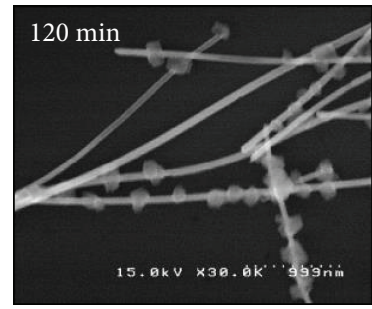

(e)

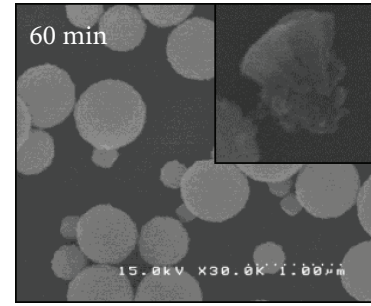

(b)

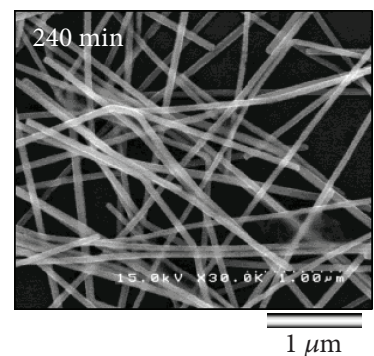

(f)

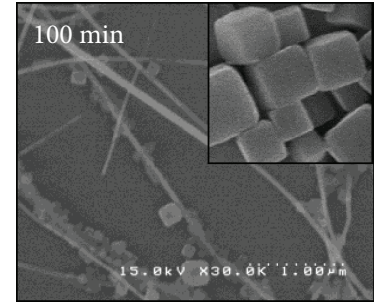

(c)

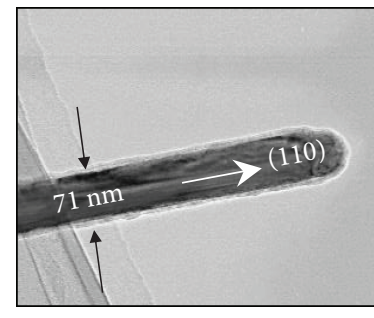

(g)

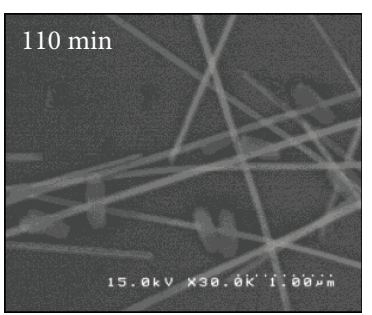

(d)

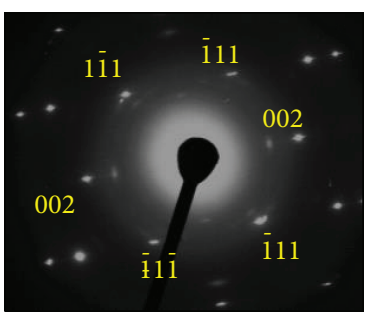

(h)

FIGURE 6: SEM images of Cu nanostructures obtained during heating at different reaction times: (a) 0, (b) 60, (c) 100, (d) 110, (e) 120, and (f) $240 \mathrm{~min}$. Insets in (b) and (c) correspond to the dissolution of the synthesized spherical $\mathrm{Cu}_{2} \mathrm{O}$ particles and the formed $\mathrm{Cu}_{2} \mathrm{O}$ cubes, respectively. (g) TEM image of Cu NWs showing the direction of growth. (h) SAED pattern of the Cu NWs.

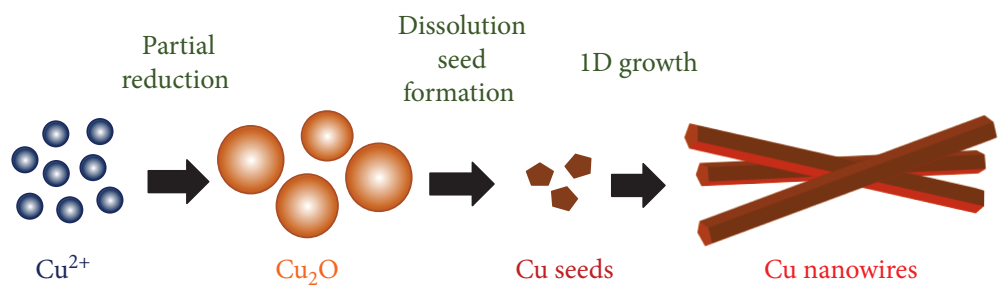

FIGURE 7: Formation scheme proposed for the synthesis of $\mathrm{Cu} N W$ s in $\mathrm{Cu}\left(\mathrm{NO}_{3}\right)_{2}$-EG-PVP system.

revealed the presence of a thin oxide layer on the wire surface indicating that PVP did not offer a good protection to the oxidation as already observed in the synthesis of $\mathrm{Cu}$ NPs by using 1-heptanol as reducing agent [43].

With the above results, the following scheme can be proposed for the formation of $\mathrm{Cu}$ NWs. At the beginning, $\mathrm{Cu}$ nitrate and ethylene glycol react to give $\mathrm{Cu}_{2} \mathrm{O}$ particles through the decomposition of copper nitrate. The evolution of $\mathrm{NO}_{2}$ gas is detected. At higher temperatures, the $\mathrm{Cu}_{2} \mathrm{O}$ particles undergo dissolution and subsequently $\mathrm{Cu}^{+}$ ions get reduced to form $\mathrm{Cu}^{0}$. The dissolution and subsequent reduction of $\mathrm{Cu}^{+}$ions to $\mathrm{Cu}^{0}$ is the rate determining a step that strikes a balance between nucleation of metallic particle and their subsequent etching to form the MTP seed. Then, the unidirectional growth of the MTPs is facilitated by the preferential absorption of the capping agent, PVP on the $\{100\}$ crystal planes of $\mathrm{Cu}$ NWs. A graphical scheme for the formation of $\mathrm{Cu}$ NWs is shown in Figure 7.

\section{Conclusions}

The synthesis of $\mathrm{Cu}$ nanowires (NWs) in high yield has been developed using $\mathrm{Cu}\left(\mathrm{NO}_{3}\right)_{2}$-EG-PVP system. A formation mechanism was proposed and summarized as follows: (1) partially reduction of $\mathrm{Cu}$ ions to $\mathrm{Cu}_{2} \mathrm{O},(2)$ redissolution of $\mathrm{Cu}_{2} \mathrm{O}$ and reduction to $\mathrm{Cu}^{0}$, (3) formation of $\mathrm{Cu}$ seeds, and (4) unidirectional growth of $\mathrm{Cu}^{0}$. The concentration of $\mathrm{Cl}^{-}$ ions and the dissolved oxygen was found vital to control the etching rate of copper seeds. Furthermore, the reaction temperature was important to obtain copper seeds in large quantities, which get etched subsequently to form and control the number of MTPs. Finally, the PVP concentration was a decisive factor that facilitates the unidirectional growth of the MTPs through specific adsorption on the $\{100\}$ planes to inhibit the lateral growth of the NWs. The NWs obtained under the optimum conditions derived in this study resulted in the synthesis of $\mathrm{Cu}$ NWs that were more 40 microns in length and $60 \mathrm{~nm}$ in diameter or aspect ratio higher than 667 that could become a potential material for the fabrication of conducting films.

\section{Data Availability}

The data used to support the findings of this study are included within the article and as well as in the supplementary materials. 


\section{Conflicts of Interest}

The authors declare that there is no conflict of interest regarding the publication of this paper.

\section{Acknowledgments}

This study was supported by Grant-in Aid for Scientific Research (B) 16H03843 and (C) 16K04891 from the Ministry of Education, Science, Culture and Sport of Japan.

\section{Supplementary Materials}

Figures S1-S4: comprehensive analysis of the formation of $\mathrm{Cu}_{2} \mathrm{O}$ and $\mathrm{CuCl}$ particles and the effect of halide sources and reaction temperature. (Supplementary Materials)

\section{References}

[1] Q. Xue, W. Yao, J. Liu et al., "Facile synthesis of silver nanowires with different aspect ratios and used as high-performance flexible transparent electrodes," Nanoscale Research Letters, vol. 12, no. 1, p. 480, 2007.

[2] M. B. Gebeyehu, T. F. Chala, S.-Y. Chang, C.-M. Wu, and J.-Y. Lee, "Synthesis and highly effective purification of silver nanowires to enhance transmittance at low sheet resistance with simple polyol and scalable selective precipitation method," RSC Advances, vol. 7, no. 26, pp. 16139-16148, 2017.

[3] R. R. da Silva, M. Yang, S.-I. Choi et al., "Facile synthesis of sub-20 nm silver nanowires through a bromide-mediated polyol method," ACS Nano, vol. 10, no. 8, pp. 7892-7900, 2016.

[4] D. V. R. Kumar, K. Woo, and J. Moon, "Promising wet chemical strategies to synthesize $\mathrm{Cu}$ nanowires for emerging electronic applications," Nanoscale, vol. 7, no. 41, pp. 1719517210, 2015.

[5] S. Bhanushali, P. Ghosh, A. Ganesh, and W. Cheng, "1D copper nanostructures: progress, challenges and opportunities," Small, vol. 11, no. 11, pp. 1232-1252, 2015.

[6] S. Ye, A. R. Rathmell, Z. Chen, I. E. Stewart, and B. J. Wiley, "Metal nanowire networks: the next generation of transparent conductors," Advanced Materials, vol. 26, no. 39, pp. 66706687, 2014.

[7] J. L. Duan, T. W. Cornelius, J. Liu et al., "Surface plasmon resonances of Cu nanowire arrays," Journal of Physical Chemistry C, vol. 113, no. 31, pp. 13583-13587, 2009.

[8] Q. Huang, C. M. Lilley, M. Bode, and R. Divan, "Surface and size effects on the electrical properties of Cu nanowires," Journal of Applied Physics, vol. 104, 2008.

[9] C. Chen, Z. Lou, and Q. Chen, "A novel way for preparing $\mathrm{Cu}$ nanowires," Chemistry Letters, vol. 34, no. 3, pp. 430-431, 2005.

[10] Y. Zhao, Y. Zhang, Y. Li, Z. He, and Z. Yan, "Rapid and largescale synthesis of $\mathrm{Cu}$ nanowires via a continuous flow solvothermal process and its application in dye-sensitized solar cells (DSSCs)," RSC Advances, vol. 2, no. 30, pp. 1154411551, 2012.

[11] D. V. R. Kumar, I. Kim, Z. Zhong, K. Kim, D. Lee, and J. Moon, " $\mathrm{Cu}(\mathrm{II})$-alkyl amine complex mediated hydrothermal synthesis of $\mathrm{Cu}$ nanowires: exploring the dual role of alkyl amines,"
Physical Chemistry Chemical Physics, vol. 16, no. 40, pp. 22107-22115, 2014.

[12] Z. Yin, C. Lee, S. Cho, J. Yoo, Y. Piao, and Y. S. Kim, "Facile synthesis of oxidation-resistant copper nanowires toward solution-processable, flexible, foldable, and free-standing electrodes," Small, vol. 10, no. 24, pp. 5047-5052, 2014.

[13] Z. Zhu, T. Mankowski, K. Balakrishnan et al., "Ultrahigh aspect ratio copper-nanowire-based hybrid transparent conductive electrodes with PEDOT:PSS and reduced graphene oxide exhibiting reduced surface roughness and improved stability," ACS Applied Materials \& Interfaces, vol. 7, no. 30, pp. 16223-16230, 2015.

[14] S. Ye, A. R. Rathmell, I. E. Stewart et al., "A rapid synthesis of high aspect ratio copper nanowires for high-performance transparent conducting films," Chemical Communications, vol. 50, no. 20, pp. 2562-2564, 2014.

[15] Y. Chang, M. L. Lye, and H. C. Zeng, "Large-scale synthesis of high-quality ultralong copper nanowires," Langmuir, vol. 21, no. 9, pp. 3746-3748, 2005.

[16] S. Ye, I. E. Stewart, Z. Chen, B. Li, A. R. Rathmell, and B. J. Wiley, "How copper nanowires grow and how to control their properties," Accounts of Chemical Research, vol. 49, no. 3, pp. 442-451, 2016.

[17] A. R. Rathmell and B. J. Wiley, "The synthesis and coating of long, thin copper nanowires to make flexible, transparent conducting films on plastic substrates," Advanced Materials, vol. 23, no. 41, pp. 4798-4803, 2011.

[18] S. Ye, A. R. Rathmell, Y.-C. Ha, A. R. Wilson, and B. J. Wiley, "The role of cuprous oxide seeds in the one-pot and seeded syntheses of copper nanowires," Small, vol. 10, no. 9, pp. 1771-1778, 2014.

[19] H. Guo, Y. Chen, H. Ping, J. Jin, and D.-L. Peng, "Facile synthesis of $\mathrm{Cu}$ and $\mathrm{Cu} @ \mathrm{Cu}-\mathrm{Ni}$ nanocubes and nanowires in hydrophobic solution in the presence of nickel and chloride ions," Nanoscale, vol. 5, no. 6, pp. 2394-2402, 2013.

[20] E. Ye, S. Y. Zhang, S. Liu, and M.-Y. Han, "Disproportionation for growing copper nanowires and their controlled selfassembly facilitated by ligand exchange," Chemistry A European Journal, vol. 17, no. 11, pp. 3074-3077, 2011.

[21] H.-J. Yang, S.-Y. He, and H.-Y. Tuan, "Self-seeded growth of five-fold twinned copper nanowires: mechanistic study, characterization, and SERS applications," Langmuir, vol. 30, no. 2, pp. 602-610, 2014.

[22] S. Wang, Y. Cheng, R. Wang, J. Sun, and L. Gao, "Highly thermal conductive copper nanowire composites with ultralow loading: toward applications as thermal interface materials," ACS Applied Materials \& Interfaces, vol. 6, no. 9, pp. 64816486, 2014.

[23] B. Wiley, T. Herricks, Y. Sun, and Y. Xia, "Polyol synthesis of silver nanoparticles: use of chloride and oxygen to promote the formation of single-crystal, truncated cubes and tetrahedrons," Nano Letters, vol. 4, no. 9, pp. 1733-1739, 2004.

[24] S. H. Im, Y. T. Lee, B. Wiley, and Y. Xia, "Large-scale synthesis of silver nanocubes: the role of $\mathrm{HCl}$ in promoting cube perfection and monodispersity," Angewandte Chemie International Edition, vol. 44, no. 14, pp. 2154-2157, 2005.

[25] H. Ding, Y. Zhang, G. Yang, S. Zhang, L. Yu, and P. Zhang, "Large scale preparation of silver nanowires with different diameters by a one-pot method and their application in 
transparent conducting films," RSC Advances, vol. 6, no. 10, pp. 8096-8102, 2016.

[26] Y. Mao, H. Yang, C. Hu, J. Guo, X. Meng, and Y. Yang, "Largescale synthesis of AgNWs with ultra-high aspect ratio above 4000 and their application in conductive thin film," Journal of Materials Science: Materials in Electronics, vol. 28, no. 7, pp. 5308-5314, 2017.

[27] K. Zhan, R. Su, S. Bai et al., "One-pot stirring-free synthesis of silver nanowires with tunable lengths and diameters via a $\mathrm{Fe}^{3+} \& \mathrm{Cl}^{-}$co-mediated polyol method and their application as transparent conductive films," Nanoscale, vol. 8, no. 42, pp. 18121-18133, 2016.

[28] M. Tsuji, K. Matsumoto, P. Jiang, R. Matsuo, X.-L. Tang, and K. S. N. Kamarudin, "Roles of Pt seeds and chloride anions in the preparation of silver nanorods and nanowires by microwave-polyol method," Colloids and Surfaces A: Physicochemical and Engineering Aspects, vol. 316, no. 1-3, pp. 266277, 2008.

[29] B. K. Park, S. Jeong, D. Kim, J. Moon, S. Lim, and J. S. Kim, "Synthesis and size control of monodisperse copper nanoparticles by polyol method," Journal of Colloid and Interface Science, vol. 311, no. 2, pp. 417-424, 2007.

[30] Y. Jainafeng, Z. Guisheng, H. Anming, and Y. N. Zhou, "Preparation of PVP coated $\mathrm{Cu}$ NPs and the application for lowtemperature bonding," Journal of Materials Chemistry, vol. 21, no. 40, pp. 15981-15986, 2011.

[31] H.-X. Zhang, U. Siegert, R. Liu, and W.-B. Cai, "Facile fabrication of ultrafine copper nanoparticles in organic solvent," Nanoscale Research Letters, vol. 4, no. 7, pp. 705-708, 2009.

[32] J. L. Cuya Huaman, K. Sato, S. Kurita, T. Matsumoto, and B. Jeyadevan, "Copper nanoparticles synthesized by hydroxyl ion assisted alcohol reduction for conducting ink," Journal of Materials Chemistry, vol. 21, no. 20, pp. 7062-7069, 2011.

[33] J. H. Rivers, K. J. Carroll, R. A. Jones, and E. E. Carpenter, "A copper-polyol complex: $\left[\mathrm{Na}_{2}\left(\mathrm{C}_{2} \mathrm{H}_{6} \mathrm{O}_{2}\right)_{6}\right]\left[\mathrm{Cu}\left(\mathrm{C}_{2} \mathrm{H}_{4} \mathrm{O}_{2}\right)_{2}\right]$," Acta Crystallographica Section C, vol. 66, no. 3, pp. m83$\mathrm{m} 85,2010$.

[34] K. J. Carroll, J. U. Reveles, M. D. Shultz, S. N. Khanna, and E. E. Carpenter, "Preparation of elemental $\mathrm{Cu}$ and Ni nanoparticles by the polyol method: an experimental and theoretical approach," Journal of Physical Chemistry C, vol. 115, no. 6, pp. 2656-2664, 2011.

[35] D. R. Whitcomb, "Copper nanowire preparation methods and compositions,” US. Patent 8764878B2, 2014.

[36] Y.-J. Song, M. Wang, X.-Y. Zhang, J.-Y. Wu, and T. Zhang, "Investigation on the role of the molecular weight of polyvinylpyrrolidone in the shape control of high-yield silver nanospheres and nanowires," Nanoscale Research Letters, vol. 9, no. 1, p. 17, 2014.

[37] J.-J. Zhu, C.-X. Kan, J.-G. Wan, M. Han, and G.-H. Wang, "High-yield synthesis of uniform Ag nanowires with high aspect ratios by introducing the long-chain PVP in an improved polyol process," Journal of Nanomaterials, vol. 2011, Article ID 982547, 7 pages, 2011.

[38] Y. Sun, B. Mayers, T. Herricks, and Y. Xia, "Polyol synthesis of uniform silver nanowires: a plausible growth mechanism and the supporting evidence," Nano Letters, vol. 3, no. 7, pp. 955-960, 2003.

[39] N. Murshid and V. Kitaev, "Role of poly(vinylpyrrolidone) (PVP) and other sterically protecting polymers in selective stabilization of $\{111\}$ and $\{100\}$ facets in pentagonally twinned silver nanoparticles," Chemical Communications, vol. 50, no. 10, pp. 1247-1249, 2014.

[40] Z. C. Li, T. M. Shang, Q. F. Zhou, and K. Feng, "Sodium chloride assisted synthesis of silver nanowires," Micro \& Nano Letters, vol. 6, no. 2, pp. 90-93, 2011.

[41] D. R. Lide, CRC Handbook of Chemistry and Physics, CRC Press, Boca Raton, FL, USA, 1995.

[42] M. Salavati-Niasara, Z. Fereshteh, and F. Davar, "Synthesis of oleylamine capped copper nanocrystals via thermal reduction of a new precursor," Polyhedron, vol. 28, no. 1, pp. 126-130, 2009.

[43] J. L. Cuya Huaman, K. Sato, S. Kurita, T. Matsumoto, H. Miyamura, and B. Jeyadevan, "Synthesis of copper nanoparticles by polyol/alcohol reduction method," MRS Proceedings, vol. 1400, 2012.

[44] C. Chen, L. Wang, G. Jiang et al., "The influence of seeding conditions and shielding gas atmosphere on the synthesis of silver nanowires through the polyol process," Nanotechnology, vol. 17, no. 2, pp. 466-474, 2006.

[45] W. Chen, L. Li, Q. Peng, and Y. Li, "Polyol synthesis and chemical conversion of $\mathrm{Cu}_{2} \mathrm{O}$ nanospheres," Nano Research, vol. 5, no. 5, pp. 320-326, 2012. 


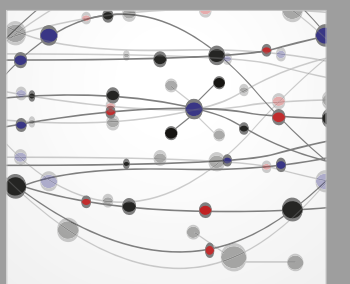

The Scientific World Journal
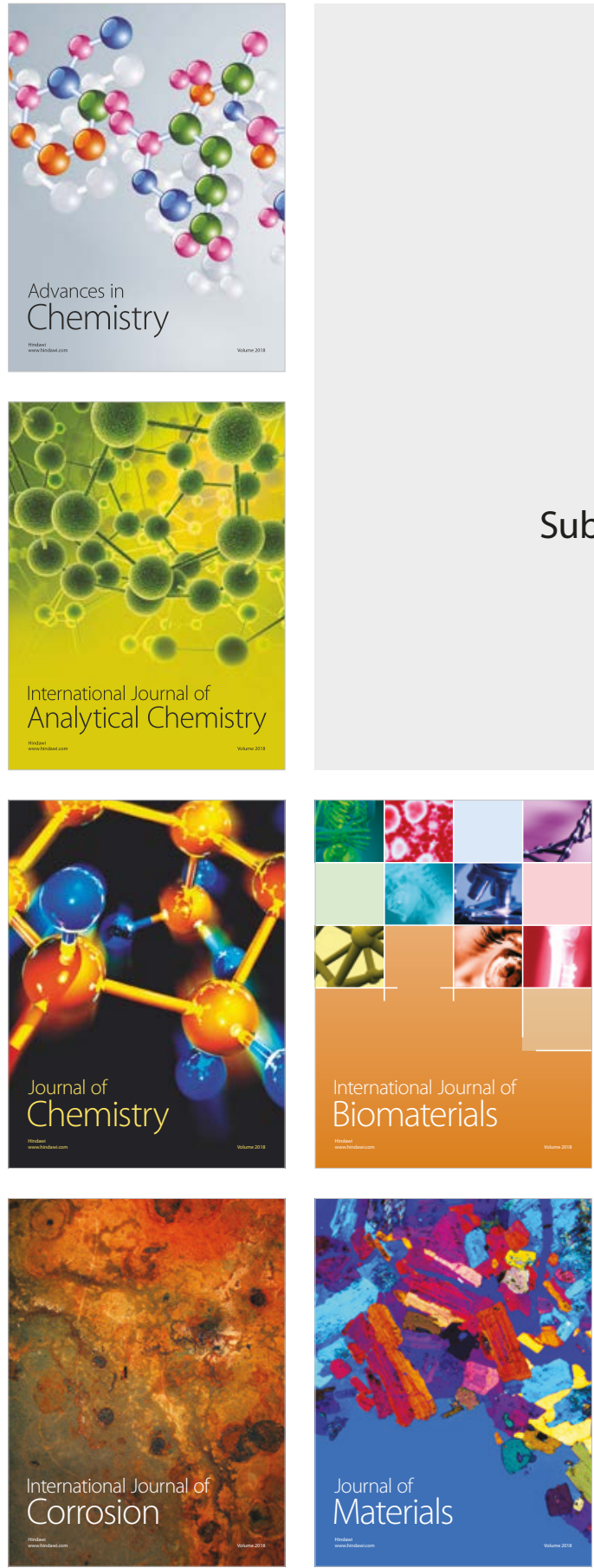

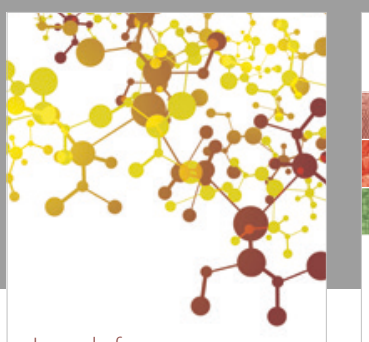

Journal of

Applied Chemistry
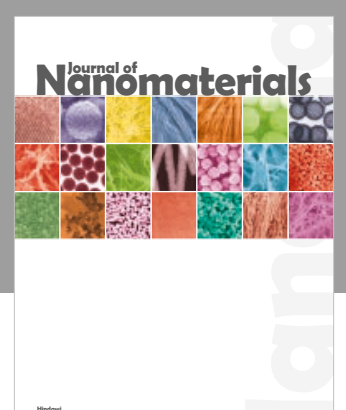

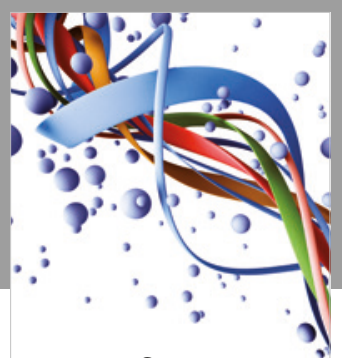

Scientifica

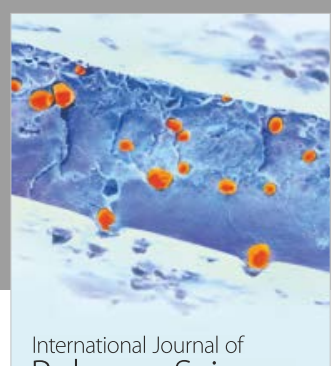

Polymer Science

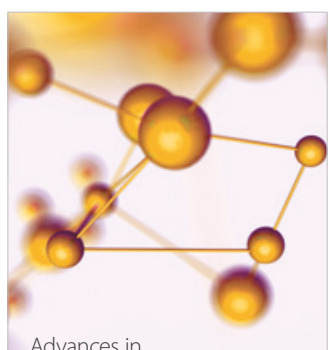

Physical Chemistry
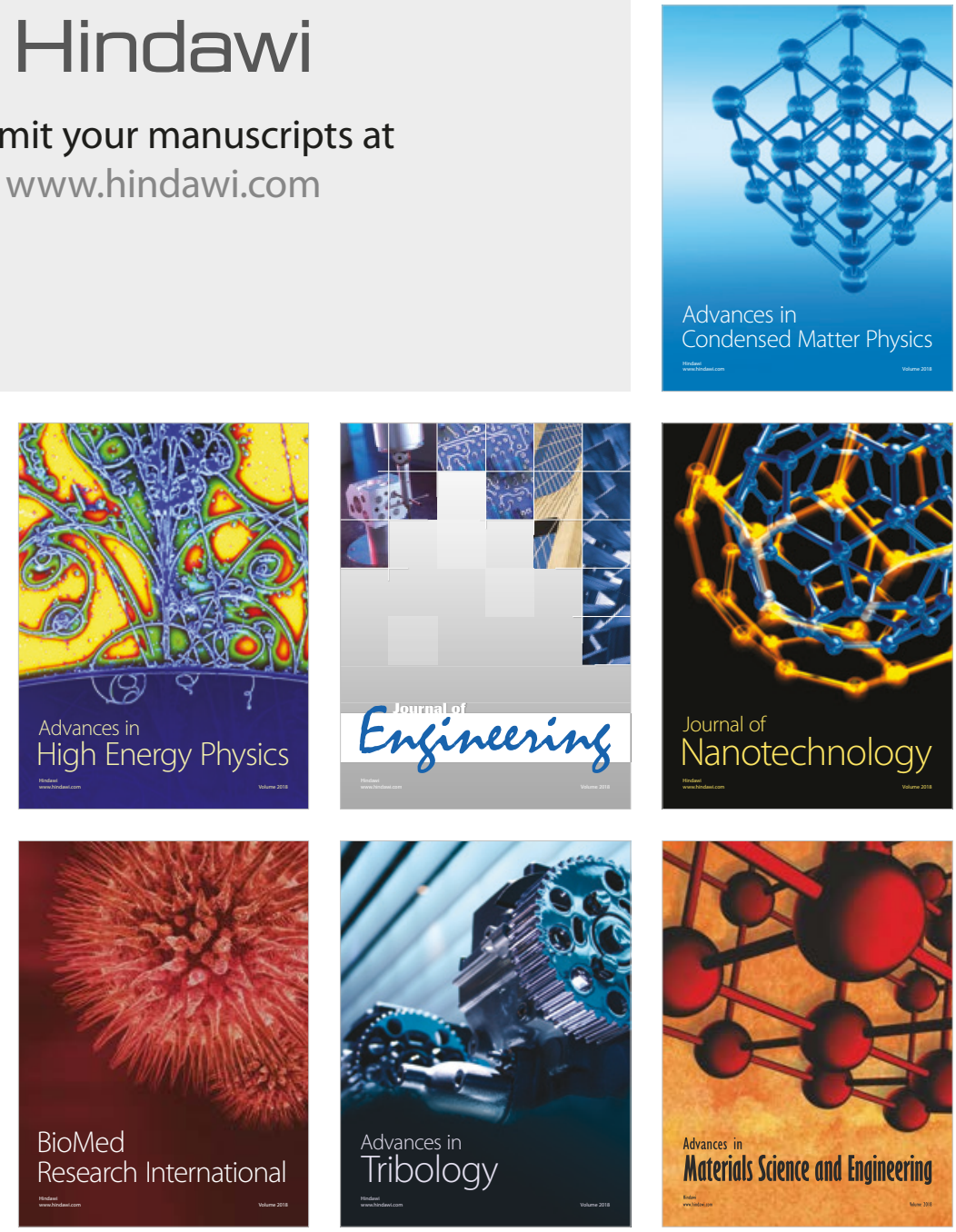